\title{
Antibiotic Practices, Perceptions and Self-Medication Among Patients at a National Referral Hospital in Uganda
}

\author{
Irene Nabaweesi ${ }^{1, *}$ \\ Ronald Olum (1D) ${ }^{1, *}$ \\ Arthur Brian Sekitel,* \\ Willy Tumwesigye Suubi ${ }^{1}$ \\ Prossy Nakiwunga ${ }^{2}$ \\ Aron Machali ${ }^{3}$ \\ Richard Kiyumba' \\ Peter Kalyango ${ }^{2}$ \\ Allen Natamba ${ }^{3}$ \\ Yokosofati Igumba' \\ Martin Kyeyune' \\ Harriet Mpairwe ${ }^{4}$ \\ Eric Katagirya ${ }^{5}$ \\ 'School of Medicine, Makerere University \\ College of Health Sciences, Kampala, \\ Uganda; ${ }^{2}$ School of Health Sciences, \\ Makerere University College of Health \\ Sciences, Kampala, Uganda; ${ }^{3}$ School of \\ Biomedical Sciences, Makerere University \\ College of Health Sciences, Kampala, \\ Uganda; ${ }^{4} \mathrm{MRC} / \mathrm{UVRI}$ and LSHTM Uganda \\ Research Unit, Entebbe, Uganda; \\ ${ }^{5}$ Department of Immunology and \\ Molecular Biology, Makerere University \\ College of Health Sciences, Kampala, \\ Uganda
}

*These authors contributed equally to this work
Correspondence: Irene Nabaweesi School of Medicine, Makerere University College of Health Sciences, P.O. Box 7072, Kampala, Uganda

Tel +256778989529

Email nabaweesiirene@yahoo.com
Background: Antimicrobial resistance (AMR) is a major global health concern with increasing reports of microorganisms resistant to most of the available antibiotics. There are limited data on antibiotic practices, perceptions and self-medication among Ugandans, necessitating this study.

Methods: A cross-sectional study was conducted among patients at Kiruddu National Referral Hospital, Kampala, Uganda. A pre-tested interviewer administered a questionnaire that was used to collect data after an informed consent. Chi-square tests and logistic regression were used to assess associations between outcome and exposure variables. A $\mathrm{P}<0.05$ was statistically significant.

Results: A total of 279 patients (response rate=71\%) with a median age of 32 years participated in the study. The majority were females $(55.6 \%, \mathrm{n}=155)$ and from the outpatient department $(74.9 \%, n=209)$. Overall, $212(76 \%)$ participants had taken an antibiotic in the past 6 months, and some $22.2 \%(n=47)$ of the participants had practiced self-medication. Male participants (adjusted odds ratio $(\mathrm{aOR})=2.13$, 95\% confidence intervals $(\mathrm{CI}): 1.01$ to 4.50, $\mathrm{P}=0.046)$ and Muslims $(\mathrm{aOR}=4.37,96 \% \mathrm{CI}: 1.54$ to $12.44, \mathrm{P}=0.006)$ were more likely to self-medicate. Employees $(\mathrm{aOR}=0.06,95 \% \mathrm{CI}: 0.01$ to $0.51, \mathrm{P}=0.010)$ and patients with tertiary education ( $\mathrm{aOR}=0.14,95 \% \mathrm{CI}$ : 0.02 to $0.81, \mathrm{P}=0.028$ ) were less likely to practice self-medication. About 33\% $(n=70)$ of the participants had not completed treatment dosage during their last course of antibiotic treatment because of feeling better $(60 \%, n=42)$, lack of money to purchase the medication $(15.7 \%, \mathrm{n}=11)$ and side effects $(10 \%, \mathrm{n}=7)$. Whereas 169 participants $(79.7 \%)$ believed that not completing treatment would have an impact on their personal health, only 96 participants $(45.3 \%)$ believed that this behaviour could affect the health of others.

Conclusion: Antibiotic misuse is significant among patients in Uganda. Continuous health education programs aimed at informing the public on antimicrobial resistance, and its dangers are recommended to curtail this challenge.

Keywords: antimicrobial resistance, antibiotic misuse, self-prescription, patients, Uganda

\section{Introduction}

Antimicrobial resistance (AMR) remains a major global health concern in the past decades. Recent studies have reported an increasing number of microorganisms resistant to most of the available antibiotics. ${ }^{1,2}$ AMR has profound implications on patients' healthcare care, costs to healthcare systems and burden to a country's economy. $^{2}$ About 700,000 people die every year due to diseases caused by drugresistant microorganisms. ${ }^{1}$ Of these, at least 230,000 deaths are caused by multi- 
drug resistant tuberculosis. It is projected that AMR could cause 10 million deaths yearly by 2050 if no action is taken to avert its development. ${ }^{1}$ Growing resistance to commonly used antibiotics has also been documented in African, ${ }^{3}$ sub-Saharan Africa, ${ }^{4}$ and East African countries, Uganda inclusive. ${ }^{5,6}$

AMR refers to the ability of a microorganism to grow in the presence of an agent or a drug that previously would kill or inhibit its growth. The development and spread of AMR have been accelerated by misuse and, or overuse of available antimicrobials in humans and agriculture, for treatment of infections in plants and animals. ${ }^{1}$ Indiscriminate prescription by healthcare workers and self-prescription by patients have been implicated, especially in developing countries faced with low patienthealth worker ratio. ${ }^{7,8}$ Poor water, sanitation and hygiene practices, improper local and industrial waste disposal management, and inadequate access to affordable and good quality antimicrobials contribute to the rising occurrence and spreading of AMR. ${ }^{1}$

Communities make significant contributions to the development and spread of AMR and therefore are great stakeholders in its prevention. Their knowledge and attitudes towards AMR influence their practices thereby playing a great role in either accelerating or curbing the spread of AMR. ${ }^{9}$ Studies have shown varying levels of self-prescription with the prevalence as high as $76 \%$ in India. ${ }^{10,11}$ There is however scarcity of data on perceptions and practices towards antibiotic misuse, including self-prescription, in Africa. A study in Eastern Ethiopia reported that close to $80 \%$ of the study population had used antibiotics a year prior to the study, and about two-thirds (65.3\%) had self-prescribed. ${ }^{12}$ Poor knowledge, perceptions and practices towards antibiotic use and AMR have also been reported in other African countries like Namibia $^{13}$ and South Africa. In South Africa, only $44 \%$ were aware of AMR associated with antibiotics overuse ${ }^{9}$ and of concern, over $45 \%$ of the participants in the study expected the doctor to prescribe two or more antibiotics for treating common cold. ${ }^{9}$

There is a scarcity of data on antibiotic misuse in Uganda. A community-based study in Northern Uganda evaluating self-medication found that up to $75.7 \%$ respondents had practiced self-medication, commonly for antimalarials, amoxicillin, metronidazole and cotrimoxazole. ${ }^{14}$ Self-medication was associated with gender, knowledge of the drug, peer advice, previous disease experience, and long distance and waiting time at health facilities. ${ }^{14}$ Irrational and indiscriminate prescription of antibiotics have also been reported in Uganda. ${ }^{8}$ In this study, we aimed to assess the perceptions and practices on antibiotic misuse including self-medication among patients seeking healthcare at Kiruddu National Referral Hospital in central Uganda.

\section{Methods and Materials Study Design}

A cross-sectional study design employing quantitative techniques was conducted between February and August, 2020.

\section{Study Area}

The study was carried out at Kiruddu National Referral Hospital. Kiruddu Hospital is one of the largest hospitals in Uganda, previously operating under Mulago Hospital Complex. It currently offers services in internal medicine, burns, plastic surgery, radiology and palliative care, and also doubles as the teaching hospital for the Department of Medicine, Makerere University College of Health Sciences. The hospital is located in Makindye Division, Kampala, approximately 13 kilometres $(8.1$ miles $)$ by road, south-east of the Mulago National Referral Hospital. The hospital serves a population of over 500 in and out patients daily.

\section{Study Population}

All patients receiving care from outpatient and inpatient departments at Kiruddu Hospital composed the study population.

\section{Inclusion and Exclusion Criteria}

All patients aged 18 years and above were eligible for the study after informed consent. Patients who were too ill (according to the interviewer's judgement) to respond to the questionnaires and those whose mental status made them unable to participate in the study were excluded.

\section{Sample Size}

The sample size was calculated using Kish Leslie formula. ${ }^{15}$ Using an estimated patient population of 5000 during the ten days of data collection, an expected knowledge of patients on antibiotic misuse of $53 \%,{ }^{9}$ and a $5 \%$ acceptable margin of error at $95 \%$ confidence interval, the calculated sample size was 356 . To cater for non-correspondents, a total of $10 \%$ of the sample size was added giving a final sample size of 392 participants. 


\section{Data Collection and Sampling Procedures}

The interviewers were trained prior to data collection on the study protocol and ethical concerns. By consecutive sampling, all patients attending IPD and OPD at the hospital who met the selection criteria were recruited in the study after an informed consent, either before or after clinical consultation. They were then assessed on antibiotic use and misuse using an interviewer-administered semistructured questionnaire. The interview with the patient was conducted in a private consulting room by the researchers to minimise response bias. A standard operating procedure was developed to guide the interviewers who were mostly medical students in their clinical years on how the interview was to be conducted. Questionnaires were checked for completeness before the participants were released from the study. An electronic data entry tool was designed using EpiCollect 5 with internal validation commands to ensure accurate data entry.

\section{Study Variables and Data Collection Tool}

The questionnaire was adapted from previous studies on antibiotic misuse and self-medication. ${ }^{10,14}$ Independent variables included demographic characteristics of the participants. These consisted of: department (IPD or OPD), age (in completed years), sex (male/female), religion, level of education (none/primary/secondary/tertiary) and employment status (unemployed/self-employed/employee/ student). The dependent variables were antibiotic misuse and perceptions towards antibiotic misuse. Participants who had taken an antibiotic in the last six months were assessed for antibiotic misuse using questions on 1) reason for taking the antibiotics, 2) dose completion and 3) selfmedication. Three close-ended questions were used to assess perceptions on antibiotic misuse. The responses were either yes, no, or I do not know.

The data collection tool was pretested among 15 patients for appropriateness and easy comprehension, and adjusted accordingly.

\section{Data Management and Analysis}

Completed questionnaires were entered using a predesigned template designed using EpiCollect 5 software and exported to Microsoft Excel 2016 for cleaning and coding. Data were then exported to STATA (StataCorp LLC, College Station, Texas, USA) for further analysis. Descriptive statistics were used to present the data. Categorical variables were presented as counts and percentages. Age was not normally distributed and was presented as median and range. Age was also categorised into young adults (youths; 18 to 35), middle-aged adults (36 to 59) and elderly (60 and above). These were presented as counts and percentages. Chi-square test, binary logistic regression and multivariable logistic regression analysis were performed to measure the association between the demographics and antibiotic misuse, dose completion, and self-medication. Results were reported as crude odds ratio (cOR), adjusted odds ratio (aOR), 95\% confidence interval (CI) and p-values. A P value less than 0.05 was considered statistically significant.

\section{Ethical Consideration}

The study was approved by The AIDS Support Organization (TASO) Research and Ethics Committee. The study was conducted in accordance with the Declaration of Helsinki. Written informed consent was obtained from all the participants before recruitment.

\section{Results}

\section{Characteristics of the Participants}

A total of 279 participants mainly from the outpatient department $(74.9 \%, \mathrm{n}=209)$ responded to the study (response rate $=71 \%$ ). Table 1 summarises the demographics of the participants. Majority of the participants were females $(55.6 \%, \mathrm{n}=155)$, aged 18 to 35 years $(58.8 \%$, $\mathrm{n}=164)$, and had attained secondary education (36.9\%, $\mathrm{n}=103)$. About $29.4 \% \quad(\mathrm{n}=82)$ of the participants subscribed to the Roman Catholic and Anglican Churches each. About $58.0 \%$ and $40.6 \%$ of the participants acquired antibiotics from private and public facilities, respectively (Figure 1).

\section{Antibiotic Practices and Perceptions}

Overall, 212 (76\%) participants had taken an antibiotic agent in the past 6 months (Table 2). Of these, $60.4 \%$ $(\mathrm{n}=128)$ had taken it for bacterial infections. Up to $17 \%$ and $12.7 \%$ had taken antibiotics for parasitic infestations and non-communicable diseases, respectively. Although some $22.2 \%(n=47)$ of the participants had practiced selfmedication, only $57.5 \%$ of these went ahead to seek professional advice from a health professional about the medication. About one-third of the participants did not complete treatment dosage during their last course of antibiotic treatment. Feeling better $(60 \%, n=42)$, lack of money to purchase the medication $(15.7 \%, \mathrm{n}=11)$ and side 
Table I Sociodemographic Characteristics of Participants

\begin{tabular}{|c|c|c|}
\hline Demographics & Frequency (n) & $\%$ \\
\hline \multicolumn{3}{|l|}{ Department } \\
\hline Outpatient Department & 209 & 74.9 \\
\hline Inpatient Department & 70 & 25.1 \\
\hline \multicolumn{3}{|l|}{ Sex } \\
\hline Female & 155 & 55.6 \\
\hline Male & 124 & 44.4 \\
\hline Age in years; median, range & 32 & 18 to 76 \\
\hline 18 to 35 & 164 & 58.8 \\
\hline 36 to 59 & 92 & 33.0 \\
\hline$\geq 60$ & 23 & 8.2 \\
\hline \multicolumn{3}{|l|}{ Religion } \\
\hline Protestant & 82 & 29.4 \\
\hline Roman Catholic & 82 & 29.4 \\
\hline Pentecostal & 48 & 17.2 \\
\hline Muslim & 45 & 16.1 \\
\hline Seventh day Adventist & 19 & 6.8 \\
\hline Atheist/None & 3 & I.I \\
\hline \multicolumn{3}{|l|}{ Occupation } \\
\hline Unemployed & 94 & 33.7 \\
\hline Self employed & 86 & 30.8 \\
\hline Employee & 70 & 25.1 \\
\hline Student & 29 & 10.4 \\
\hline \multicolumn{3}{|l|}{ Level of education } \\
\hline None & 15 & 5.4 \\
\hline Primary & 92 & 33.0 \\
\hline Secondary & 103 & 36.9 \\
\hline Tertiary & 69 & 24.7 \\
\hline
\end{tabular}

Notes: $\mathrm{n}$ denotes number of participants, \% denotes proportion of participants.

effects $(10 \%, \mathrm{n}=7)$ were the most common reasons for not completing treatment dosage.

Overall, $143(67.5 \%)$ participants perceived that an antibiotic will always be effective in the treatment of the same infection in future. Whereas 169 participants (79.7\%) believed that not completing treatment would have an impact on their personal health, only 96 participants $(45.3 \%)$ believed that this behaviour could affect the health of others.

Factors Associated with Antibiotic Misuse Overall, 84 patients $(40 \%)$ had used antibiotics to treat other diseases (fungal, parasitic, viral and non-communicable) other than bacterial infections. Majority of these were from the outpatient department $(78.6 \%, \mathrm{n}=66)$, females $(59.5 \%, \mathrm{n}=50)$, and youths aged 18 to 35 years $(50 \%, \mathrm{n}=42)$. Unemployed patients $(38.1 \%, \mathrm{n}=32)$ and those who had attained a maximum of primary education $(35.7 \%, \mathrm{n}=30)$ also frequently misused antibiotics. These relationships were, however, not significant in both bivariate and multivariable analyses (Table 3).

\section{Factors Associated with Antibiotic Dose Completion}

Overall, one-third of the patients $(n=70)$ had not completed their antibiotic doses during their last treatment. Of these, majority were from the outpatient department $(78.6 \%, \mathrm{n}=55)$, females $(65.7 \%, \mathrm{n}=46)$ and those aged 18 to $35(57.1 \%, \mathrm{n}=40)$. In the bivariate analysis, dose completion was associated with occupation $(\mathrm{P}=0.023)$; participants who were self-employed were twice as likely to complete treatment doses than their unemployed counterparts (cOR: $2.02,95 \%$ CI: $1.01-4.03, \mathrm{P}=0.046$ ). There was no significant association between all the demographics with dose completion in multivariate analysis (Table 4).

\section{Factors Associated with Self-Medication}

Table 5 shows the results of the bivariate and multivariable analyses. At bivariate analysis, Muslims (cOR: 3.64, 95\% CI: $1.37-9.68, \mathrm{P}=0.010$ ) were more likely to self-medicate, whereas participants who were employees were less likely to self-medicate (cOR: 0.08, 95\% CI: 0.01-0.59, $\mathrm{P}=0.014$ ). In multivariable logistic regression, male participants were twice as likely to take medications without prescriptions than their female counterparts (adjusted odds ratio (aOR) $=2.13,95 \%$ confidence intervals $(\mathrm{CI}): 1.01$ to 4.50 , $\mathrm{P}=0.046$ ). Muslims were also four times more likely to self-medicate $\quad(\mathrm{aOR}=4.37,96 \%$ CI:1.54 to 12.44 , $\mathrm{P}=0.006$ ). Self-employed patients formed the majority of those who self-medicated $(48.9 \%, \mathrm{n}=23)$; however, this association was not statistically significant. On the other hand, employees $(\mathrm{aOR}=0.06,95 \% \mathrm{CI}: 0.01$ to 0.51 , $\mathrm{P}=0.010$ ) and patients with at least tertiary education ( $\mathrm{aOR}=0.14,95 \% \mathrm{CI}: 0.02$ to $0.81, \mathrm{P}=0.028$ ) were less likely to practice self-medication.

\section{Discussion}

Antimicrobial resistance continues to be a major health threat globally. ${ }^{16}$ Antibiotic misuse is one of the major driving factors for AMR, especially in developing countries, Uganda inclusive. ${ }^{8,16}$ Developing countries have multiple challenges in healthcare access, including inadequate infrastructure and health workers. In Uganda, the doctor-to-patient ratio is $1: 25,725$ patients and 11,000 


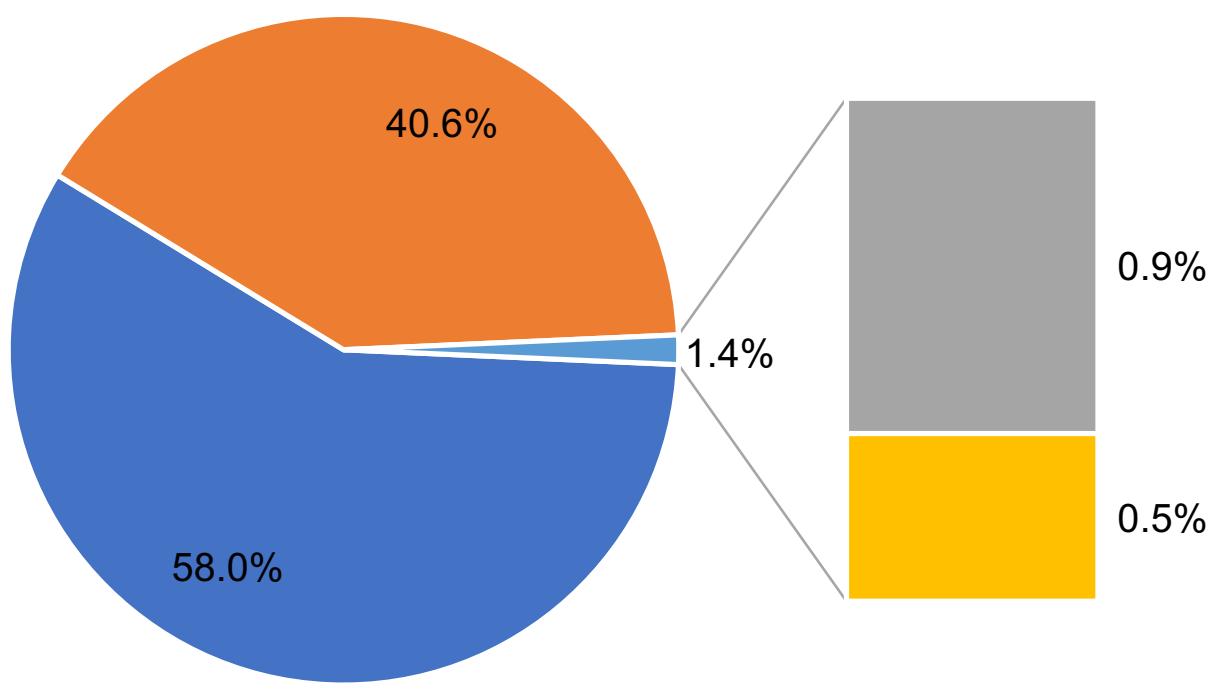

- Private facility. $=$ Public facility. $=$ Left-overs $=$ Friends or relatives

Figure I Sources of antibiotics among participants.

patients per nurse. ${ }^{17}$ In addition, there were about 316 registered pharmacists in Uganda in 2017 with only 36 working in the public sector. ${ }^{18}$ This human resource for health burden can have an impact on the trends in antibiotic misuse and self-prescription. In our study, we assessed the practices and perceptions associated with antibiotic misuse and self-medication among patients at Kiruddu National Referral Hospital.

Our results showed that up to $76 \%$ of the respondents had taken antibiotics in the last six months, which was less than $96 \%$ that was reported by a previous study among the general public in Qatar. ${ }^{19}$ The high rate of antibiotic usage can be attributed to the indiscriminate and excessive prescription of antibiotics by drug shops in Uganda, described by Mbonye and colleagues. ${ }^{8}$ The high rate of prescribing could be explained by patient pressure exerted on health workers to prescribe antibiotics even when they are not needed, as well as inadequate training of health workers on antibiotic prescription. ${ }^{8}$ Previous studies have shown that patients could influence the decisions of physicians while prescribing antibiotics, which in turn can lead to overprescription. ${ }^{20,21}$ Previous research pointed to the fact that physicians may overestimate patients' expectations for getting antibiotics and undervalue the necessity of conducting diagnostic tests necessary to confirm the need for antibiotics. ${ }^{20}$
From the study results, $22.2 \%$ of the respondents had self-medicated which is lower than those reported in Ethiopia, Namibia and South Africa. ${ }^{9,12,13}$ A study conducted in Peru in 1000 college students showed that approximately $70 \%$ of the participants used antibiotics without medical consultation. ${ }^{22}$ In a systematic review of public knowledge and behaviors relating to antibiotic use in the Gulf Cooperation Council (GCC) countries, the authors reported that the overall prevalence of antibiotic self-medication reached $73 \%$, with Saudi Arabia having the highest prevalence. ${ }^{23}$ These findings, along with other studies in Qatar indicate the need for public education about the appropriate use of antibiotics and the risks associated with their misuse. ${ }^{23}$ Patients who had attained tertiary education and those with employment were less likely to self-medicate compared to their colleagues; which can be attributed to a better socioeconomic status and hence able to afford proper healthcare. Males were also more likely to self-medicate which is in line with the study in Northern Uganda. ${ }^{14}$ Men tend to have poor health seeking behaviour compared to women, hence a possibility of opting for self-medication. ${ }^{24}$

This study also found an association between religion and self-medication in our study, particularly among the Muslims. This was in contrast to a similar study in Nigeria which reported that Christians were 
Table 2 Antibiotic Misuse Practices and Perceptions

\begin{tabular}{|c|c|c|c|}
\hline & Question ( $N=279)$ & Frequency (n) & $\%$ \\
\hline 1 & $\begin{array}{l}\text { In the last six months, have you taken any antibiotics? } \\
\text { Yes } \\
\text { No }\end{array}$ & $\begin{array}{c}212 \\
67\end{array}$ & $\begin{array}{l}76.0 \\
24.0\end{array}$ \\
\hline 2 & $\begin{array}{l}\text { If yes above, continue with the study }(n=2 \mid 2) \text {. What was the most frequent } \\
\text { reason for taking antibiotics? } \\
\text { Bacterial infection } \\
\text { Parasitic infection } \\
\text { Non communicable disease } \\
\text { Viral infection } \\
\text { Fungal infection }\end{array}$ & $\begin{array}{l}128 \\
36 \\
27 \\
12 \\
9\end{array}$ & $\begin{array}{l}60.4 \\
17.0 \\
12.7 \\
5.7 \\
4.3\end{array}$ \\
\hline $3 a$ & $\begin{array}{l}\text { Do you take all antibiotics with prescription? } \\
\text { Yes } \\
\text { No }\end{array}$ & $\begin{array}{c}165 \\
47\end{array}$ & $\begin{array}{l}77.8 \\
22.2\end{array}$ \\
\hline $3 b$ & $\begin{array}{l}\text { If no, did you seek advice from any of the other health care professional? } \\
\text { Yes } \\
\text { No }\end{array}$ & $\begin{array}{l}27 \\
20\end{array}$ & $\begin{array}{l}57.5 \\
42.6\end{array}$ \\
\hline $4 a$ & $\begin{array}{l}\text { During your last treatment, did you complete the dose? } \\
\text { Yes } \\
\text { No }\end{array}$ & $\begin{array}{c}142 \\
70\end{array}$ & $\begin{array}{l}67.0 \\
33.0\end{array}$ \\
\hline $4 b$ & $\begin{array}{l}\text { If no, why? } \\
\text { I got better. } \\
\text { Lack of money } \\
\text { Side effects of the medication } \\
\text { There was no improvement. } \\
\text { I forgot. } \\
\text { Shortage of medication }\end{array}$ & $\begin{array}{c}42 \\
11 \\
7 \\
5 \\
3 \\
2\end{array}$ & $\begin{array}{c}60.0 \\
15.7 \\
10.0 \\
7.1 \\
4.3 \\
2.9\end{array}$ \\
\hline 5 & $\begin{array}{l}\text { An antibiotic will always be effective in the treatment of same infection in future } \\
\text { Yes } \\
\text { No } \\
\text { I do not know. }\end{array}$ & $\begin{array}{l}143 \\
42 \\
27\end{array}$ & $\begin{array}{l}67.5 \\
19.8 \\
12.7\end{array}$ \\
\hline 6 & $\begin{array}{l}\text { Not finishing the dose has an impact on my health } \\
\text { Yes } \\
\text { I do not know. } \\
\text { No }\end{array}$ & $\begin{array}{l}169 \\
27 \\
16\end{array}$ & $\begin{array}{l}79.7 \\
12.7 \\
7.6\end{array}$ \\
\hline 7 & $\begin{array}{l}\text { Not finishing the dose has an impact on the health of others } \\
\text { Yes } \\
\text { No } \\
\text { I do not know. }\end{array}$ & $\begin{array}{l}96 \\
69 \\
47\end{array}$ & $\begin{array}{l}45.3 \\
32.6 \\
22.2\end{array}$ \\
\hline
\end{tabular}

Notes: $\mathrm{n}$ denotes number of participants, \% denotes proportion of participants.

more likely to self-medicate. ${ }^{25}$ Among health sciences students in Ethiopia, both being Muslim and Protestant (Anglican) were significantly associated with selfmedication $^{26}$ and similar findings have been reported among pregnant women in Ethiopia. ${ }^{27}$ While it is challenging to find plausible explanations for this consistent finding, a qualitative study may provide an insight on how the various religious practices influence health-seeking behaviour, particularly self-medication.

The burden of antibiotic self-medication is increasing and becoming a global health threat due to emerging antibiotics resistance. ${ }^{7}$ The adverse health outcomes of 
Table 3 Factors Associated with Antibiotic Misuse Among Patients at Kiruddu National Referral Hospital

\begin{tabular}{|c|c|c|c|c|c|c|c|}
\hline \multirow[t]{2}{*}{ Demographics } & \multicolumn{2}{|c|}{ Antibiotic Misuse } & \multirow{2}{*}{$\begin{array}{c}\mathbf{C h i}^{\mathbf{2}} \\
\text { Test } \\
\mathbf{P}\end{array}$} & \multicolumn{4}{|c|}{ Logistic Regression } \\
\hline & Yes & No & & COR & $\mathbf{P}$ & aOR $(95 \% \mathrm{Cl})$ & $\mathbf{P}$ \\
\hline \multicolumn{8}{|l|}{ Department } \\
\hline Inpatient Department & $18(2 \mid .4)$ & $36(28.1)$ & 0.274 & 1.00 & & 1.00 & \\
\hline Outpatient Department & $66(78.6)$ & $92(71.9)$ & & $1.43(0.75-2.74)$ & 0.275 & $1.4(0.7 \mid-2.73)$ & 0.329 \\
\hline \multicolumn{8}{|l|}{ Sex } \\
\hline Female & $50(59.5)$ & $73(57)$ & 0.719 & 1.00 & & 1.00 & \\
\hline Male & $34(40.5)$ & $55(43)$ & & $0.90(0.52-1.58)$ & 0.719 & $0.94(0.52-1.72)$ & 0.843 \\
\hline \multicolumn{8}{|l|}{ Age; median, range } \\
\hline 18 to 35 & $42(50)$ & $72(56.3)$ & 0.671 & 1.00 & & 1.00 & \\
\hline 36 to 59 & $33(39.3)$ & $44(34.4)$ & & I.28 (0.7I-2.32) & 0.404 & I.4I (0.73-2.72) & 0.305 \\
\hline$\geq 60$ & $9(10.7)$ & $12(9.4)$ & & $1.29(0.50-3.31)$ & 0.602 & $1.36(0.48-3.85)$ & 0.563 \\
\hline \multicolumn{8}{|l|}{ Religion } \\
\hline Roman Catholic & $26(31)$ & $4 I(32)$ & 0.626 & 1.00 & & 1.00 & \\
\hline Protestant & $26(3 \mathrm{I})$ & 37 (28.9) & & I.II (0.55-2.23) & 0.774 & $1.14(0.55-2.37)$ & 0.717 \\
\hline Muslim & $13(15.5)$ & $23(18)$ & & $0.89(0.39-2.06)$ & 0.788 & $0.91(0.38-2.15)$ & 0.824 \\
\hline Pentecostal & $14(16.7)$ & $21(16.4)$ & & $1.05(0.46-2.43)$ & 0.907 & $0.9(0.37-2.18)$ & 0.813 \\
\hline Seventh day Adventist & $5(6)$ & $3(2.3)$ & & $2.63(0.58-11.94)$ & 0.211 & $2.62(0.55-12.47)$ & 0.225 \\
\hline Atheist/None & $0(0)$ & $3(2.3)$ & & NA & & NA & \\
\hline \multicolumn{8}{|l|}{ Occupation } \\
\hline Unemployed & $32(38.1)$ & $45(35.2)$ & 0.674 & 1.00 & & 1.00 & \\
\hline Self employed & $29(34.5)$ & $47(36.7)$ & & $0.86(0.45-1.66)$ & 0.668 & $0.82(0.4 I-I .62)$ & 0.561 \\
\hline Employee & $14(16.7)$ & $27(21.1)$ & & $0.73(0.33-1.60)$ & 0.433 & $0.7 \mid(0.3-1.7)$ & 0.444 \\
\hline Student & $9(10.7)$ & $9(7)$ & & I.4I (0.50-3.94) & 0.516 & I.44 (0.44-4.74) & 0.55 \\
\hline \multicolumn{8}{|l|}{ Level of education } \\
\hline None & $6(7.1)$ & $8(6.3)$ & 0.515 & 1.00 & & 1.00 & \\
\hline Primary & $30(35.7)$ & $46(35.9)$ & & $0.87(0.27-2.76)$ & 0.812 & $0.76(0.22-2.64)$ & 0.664 \\
\hline Secondary & $26(3 I)$ & $50(39.1)$ & & $0.69(0.22-2.21)$ & 0.536 & $0.68(0.19-2.42)$ & 0.548 \\
\hline Tertiary & $22(26.2)$ & $24(18.8)$ & & $1.22(0.37-4.08)$ & 0.744 & $1.12(0.29-4.23)$ & 0.871 \\
\hline
\end{tabular}

Note: NA, category not included in the logistic regression model due to insufficient number of observations.

Abbreviations: aOR, adjusted odds ratio; $\mathrm{COR}$, crude odds ratio; $\mathrm{Cl}$, confidence interval.

such practices should always be stressed individuals within the community in order to reduce it. ${ }^{7}$ Frequent irrational antimicrobial use without proper prescription from health professionals can result in increased rates of inappropriate, incorrect, or unjustified treatment, missed or incorrect diagnosis, delays in receiving the right treatment, emergence of pathogen resistance and increased morbidity and mortality. ${ }^{7}$ The majority of patients in our study were aware that antibiotic misuse had health implications on their personal health; however, less than half believed it had an impact on the health of others.
Usage of antibiotics for treatment of diseases other than bacterial infections was significant in our study with parasitic infections being the most common. This is in line with other studies that have reported high use of antibiotics frequently for common colds and flu. ${ }^{9,12}$ This can be attributed to self-diagnosis by the patients which may be wrong diagnoses in many cases, subsequently leading to purchase and consumption of antibiotics. ${ }^{7}$ Increased costs of access to quality health care and consultations from well-trained medical professionals also predispose patients with low socio-economic status to opt for self-diagnosis. ${ }^{7}$ 
Table 4 Factors Associated with Antibiotic Dose Completion Among Patients at Kiruddu National Referral Hospital

\begin{tabular}{|c|c|c|c|c|c|c|c|}
\hline \multirow[t]{2}{*}{ Demographics } & \multicolumn{2}{|c|}{ Dose Completion } & \multirow{2}{*}{$\frac{\text { Chi }^{2} \text { Test }}{\mathbf{P}}$} & \multicolumn{4}{|c|}{ Logistic Regression } \\
\hline & Yes (\%) & No (\%) & & COR & $\mathbf{P}$ & aOR $(95 \% \mathrm{Cl})$ & $\mathbf{P}$ \\
\hline \multicolumn{8}{|l|}{ Department } \\
\hline Inpatient Department & $39(27.5)$ & $15(21.4)$ & 0.343 & 1.00 & & 1.00 & \\
\hline Outpatient Department & $103(72.5)$ & $55(78.6)$ & & $0.72(0.37-I .42)$ & 0.344 & $0.78(0.38-1.60)$ & 0.492 \\
\hline \multicolumn{8}{|l|}{ Sex } \\
\hline Female & $77(54.2)$ & $46(65.7)$ & 0.111 & 1.00 & & 1.00 & \\
\hline Male & $65(45.8)$ & $24(34.3)$ & & $1.62(0.89-2.93)$ & 0.112 & I.5 (0.78-2.86) & 0.223 \\
\hline \multicolumn{8}{|l|}{ Age } \\
\hline 18 to 35 & $74(52.1)$ & $40(57.1)$ & 0.753 & 1.00 & & 1.00 & \\
\hline 36 to 59 & $54(38)$ & $23(32.9)$ & & $1.27(0.68-2.36)$ & 0.452 & I.I5 (0.56-2.35) & 0.697 \\
\hline$\geq 60$ & $14(9.9)$ & $7(10)$ & & $1.08(0.40-2.90)$ & 0.877 & $1.16(0.38-3.59)$ & 0.792 \\
\hline \multicolumn{8}{|l|}{ Religion } \\
\hline Roman Catholic & $45(31.7)$ & $22(31.4)$ & 0.710 & 1.00 & & 1.00 & \\
\hline Protestant & $45(31.7)$ & $18(25.7)$ & & $1.22(0.58-2.58)$ & 0.599 & $1.07(0.48-2.36)$ & 0.872 \\
\hline Pentecostal & $23(16.2)$ & $12(17.1)$ & & $0.68(0.30-1.58)$ & 0.374 & $1.20(0.47-3.08)$ & 0.708 \\
\hline Muslim & $21(14.8)$ & $15(21.4)$ & & $0.94(0.39-2.22)$ & 0.883 & $0.60(0.25-1.45)$ & 0.257 \\
\hline Seventh day Adventist & $5(3.5)$ & $3(4.3)$ & & $0.81(0.18-3.72)$ & 0.792 & $0.74(0.15-3.76)$ & 0.719 \\
\hline Atheist/None & $3(2.1)$ & $0(0)$ & & NA & & $\mathrm{N} / \mathrm{A}$ & \\
\hline \multicolumn{8}{|l|}{ Occupation } \\
\hline Unemployed & $46(32.4)$ & $31(44.3)$ & 0.023 & 1.00 & & 1.00 & \\
\hline Employee & $31(21.8)$ & $10(14.3)$ & & $2.09(0.9-4.87)$ & 0.088 & $1.94(0.77-4.89)$ & 0.161 \\
\hline Self employed & $57(40.1)$ & $19(27.1)$ & & $2.02(1.01-4.03)$ & 0.046 & $\mathrm{I} .83(0.88-3.8 \mathrm{I})$ & 0.106 \\
\hline Student & $8(5.6)$ & $10(14.3)$ & & $0.54(0.19-1.52)$ & 0.242 & $0.51(0.15-1.73)$ & 0.279 \\
\hline \multicolumn{8}{|l|}{ Level of education } \\
\hline None & $7(4.9)$ & $7(10)$ & 0.236 & & & 1.00 & \\
\hline Primary & $51(35.9)$ & $25(35.7)$ & & $2.04(0.64-6.45)$ & 0.225 & $2.20(0.61-7.88)$ & 0.226 \\
\hline Secondary & $56(39.4)$ & $20(28.6)$ & & $2.80(0.87-8.98)$ & 0.083 & $3.09(0.83-11.47)$ & 0.092 \\
\hline Tertiary & $28(19.7)$ & $18(25.7)$ & & $1.56(0.47-5.18)$ & 0.472 & $1.86(0.47-7.33)$ & 0.372 \\
\hline
\end{tabular}

Note: NA, category not included in the logistic regression model due to insufficient number of observations. Abbreviations: aOR, adjusted odds ratio; $\mathrm{COR}$, crude odds ratio; $\mathrm{Cl}$, confidence interval.

Previous experience with a disease condition has also been shown to be associated with self-diagnosis and thus selfmedication in Uganda, thus it was not surprising that for a good number of patients, our study received prescriptions from their family members. ${ }^{14}$

\section{Limitations}

This study relied on self-report by the patients to define antibiotic use and misuse. This is liable to recall or response bias and should be taken into consideration when interpreting the findings of this study. However, a standard interviewer guide was developed by the investi- gators to assist patients distinguish between antibiotics and other drugs. Data were also collected by medical students who had completed pharmacology course units and had a good understanding of drug classes.

\section{Conclusion}

Antibiotic misuse is significant among patients in Uganda. Continuous health education programs aimed at informing the public on antimicrobial resistance and its dangers are recommended to curb this practice. Regulation of prescription practices as well as refresher training for health workers on antibiotic prescription is urgent. 
Table 5 Factors Associated with Self-Medication Among Patients at Kiruddu National Referral Hospital

\begin{tabular}{|c|c|c|c|c|c|c|c|}
\hline \multirow[t]{2}{*}{ Demographics } & \multicolumn{2}{|c|}{ Self-Medication } & \multirow{2}{*}{$\frac{\mathbf{X} 2}{\mathbf{P}}$} & \multicolumn{4}{|c|}{ Logistic Regression } \\
\hline & Yes (\%) & No (\%) & & COR & $\mathbf{P}$ & aOR $(95 \% \mathrm{Cl})$ & $\mathbf{P}$ \\
\hline \multicolumn{8}{|l|}{ Department } \\
\hline Inpatient Department & I4 (29.8) & $40(24.2)$ & $0.44 I$ & 1.00 & & 1.00 & \\
\hline Outpatient Department & $33(70.2)$ & $125(75.8)$ & & $0.75(0.37-1.55)$ & 0.442 & $0.96(0.43-2.16)$ & 0.921 \\
\hline \multicolumn{8}{|l|}{ Sex } \\
\hline Female & $22(46.8)$ & $101(61.2)$ & 0.078 & 1.00 & & 1.00 & \\
\hline Male & $25(53.2)$ & $64(38.8)$ & & $1.79(0.93-3.45)$ & 0.080 & $2.13(1.01-4.5)$ & 0.046 \\
\hline \multicolumn{8}{|l|}{ Age; median, range } \\
\hline 18 to 35 & $22(46.8)$ & $92(55.8)$ & 0.542 & 1.00 & & 1.00 & \\
\hline 36 to 59 & $20(42.6)$ & $57(34.5)$ & & $1.47(0.74-2.92)$ & 0.276 & $1.36(0.58-3.17)$ & 0.483 \\
\hline$\geq 60$ & $5(10.6)$ & $16(9.7)$ & & $1.31(0.43-3.95)$ & 0.636 & $0.73(0.2-2.63)$ & 0.630 \\
\hline \multicolumn{8}{|l|}{ Religion } \\
\hline Roman Catholic & $9(19.1)$ & $58(35.2)$ & 0.079 & 1.00 & & 1.00 & \\
\hline Protestant & $15(31.9)$ & $48(29.1)$ & & $2.0 \mathrm{I}(0.8 \mathrm{I}-5.0 \mathrm{I})$ & 0.132 & $2.39(0.9-6.35)$ & 0.080 \\
\hline Muslim & $13(27.7)$ & $23(13.9)$ & & $3.64(1.37-9.68)$ & 0.010 & $4.37(1.54-12.44)$ & 0.006 \\
\hline Pentecostal & $9(19.1)$ & $26(15.8)$ & & $2.23(0.79-6.27)$ & 0.128 & $2.97(0.94-9.37)$ & 0.063 \\
\hline Seventh day Adventist & $0(0)$ & $8(4.8)$ & & NA & & NA & \\
\hline Atheist/None & $\mathrm{I}(2.1)$ & $2(1.2)$ & & $3.22(0.26-39.3)$ & 0.359 & $3.55(0.18-69.26)$ & 0.403 \\
\hline \multicolumn{8}{|l|}{ Occupation } \\
\hline Unemployed & $19(40.4)$ & $58(35.2)$ & 0.006 & 1.00 & & 1.00 & \\
\hline Self employed & $23(48.9)$ & $53(32.1)$ & & $1.32(0.65-2.7)$ & 0.439 & I.I2(0.5-2.54) & 0.781 \\
\hline Employee & $\mathrm{I}(2.1)$ & $40(24.2)$ & & $0.08(0.01-0.59)$ & 0.014 & $0.06(0.01-0.5 \mathrm{I})$ & 0.010 \\
\hline Student & $4(8.5)$ & $14(8.5)$ & & $0.87(0.26-2.97)$ & 0.827 & I.I (0.25-4.92) & 0.896 \\
\hline \multicolumn{8}{|l|}{ Level of education } \\
\hline None & $5(10.6)$ & $9(5.5)$ & 0.148 & 1.00 & & 1.00 & \\
\hline Primary & $19(40.4)$ & $57(34.5)$ & & $0.6(0.18-2.01)$ & 0.408 & $0.44(0.1-1.85)$ & 0.262 \\
\hline Secondary & $18(38.3)$ & $58(35.2)$ & & $0.56(0.17-1.88)$ & 0.347 & $0.46(0.1-2.04)$ & 0.306 \\
\hline Tertiary & $5(10.6)$ & $4 \mid(24.8)$ & & $0.22(0.05-0.92)$ & 0.038 & $0.14(0.02-0.81)$ & 0.028 \\
\hline
\end{tabular}

Note: NA, category not included in the logistic regression model due to insufficient number of observations. Abbreviations: $\mathrm{aOR}$, adjusted odds ratio; cOR, crude odds ratio; $\mathrm{Cl}$, confidence interval.

\section{Acknowledgment}

We acknowledge the support and guidance provided by the HEPI secretariat in the development of this study and acquisition of funding.

\section{Author Contributions}

All authors made substantial contributions to conception and design, acquisition of data, or analysis and interpretation of data, took part in drafting the article or revising it critically for important intellectual content, agreed to submit to the current journal, gave final approval for the version to be published, and agreed to be accountable for all aspects of the work.

\section{Funding}

Research reported in this publication was supported by the Fogarty International Center of the National Institutes of Health, US Department of State's Office of the US Global AIDS Coordinator and Health Diplomacy (S/GAC), and President's Emergency Plan for AIDS Relief (PEPFAR) under Award Number 1R25TW011213. The content is solely the responsibility of the authors and does not necessarily represent the official views of the National Institutes of Health.

\section{Disclosure}

The authors declare no conflicts of interests. 


\section{References}

1. IACG. No Time to Wait: Securing the Future from Drug-Resistant Infections. Report to the Secretary-General of the United Nations. 2019.

2. Naylor NR, Atun R, Zhu N, et al. Estimating the burden of antimicrobial resistance: a systematic literature review. Antimicrob Resist Infect Control. 2018;7(1):58. doi:10.1186/s13756-018-0336-y

3. Tadesse BT, Ashley EA, Ongarello S, et al. Antimicrobial resistance in Africa: a systematic review. BMC Infect Dis. 2017;17(1):616. doi:10.1186/s12879-017-2713-1

4. Elton L, Thomason MJ, Tembo J, et al. Antimicrobial resistance preparedness in sub-Saharan African countries. Antimicrob Resist Infect Control. 2020;9(1):145. doi:10.1186/s13756-020-00800-y

5. Ampaire L, Muhindo A, Orikiriza P, et al. A review of antimicrobial resistance in East Africa. Afr J Lab Med. 2016;5(1). doi:10.4102/ ajlm.v5i1.432

6. Wangai FK, Masika MM, Lule GN, et al. Bridging antimicrobial resistance knowledge gaps: the East African perspective on a global problem. PLoS One. 2019;14(2):e0212131. doi:10.1371/journal.pone.0212131

7. Bennadi D. Self-medication: a current challenge. J Basic Clin Pharm. 2014;5(19).

8. Mbonye AK, Buregyeya E, Rutebemberwa E, et al. Prescription for antibiotics at drug shops and strategies to improve quality of care and patient safety: a cross-sectional survey in the private sector in Uganda. BMJ Open. 2016;6(3):e010632. doi:10.1136/bmjopen-2015-010632

9. Ramchurren K, Balakrishna Y, Mahomed S. Patients' knowledge, attitudes and practices regarding antibiotic use at a regional hospital in KwaZulu-Natal, South Africa 2017. S Afr J Infect Dis. 2018;1-6. doi:10.1080/23120053.2018.1516393

10. Chandrakanth P, Mohamed Saleem TS, Reddy MM, Gopinath C, Rao MM. Assessment of public knowledge and attitude regarding antibiotic use in a tertiary care hospital. Asian J Pharm Clin Res. 2016;9:83-87.

11. Limaye D, Limaye V, Krause G, Fortwengel G. A systematic review of the literature on survey questionnaires to assess self-medication practices. Int J Commun Med Public Health. 2017;4(8):2620. doi:10.18203/2394-6040.ijemph20173192

12. Jifar A, Ayele Y. Assessment of knowledge, attitude, and practice toward antibiotic use among Harar city and its surrounding community, Eastern Ethiopia. Interdiscip Perspect Infect Dis. 2018;2018:16. doi:10.1155/2018/8492740

13. Pereko DD, Lubbe MS, Essack SY. Public knowledge, attitudes and behaviour towards antibiotic usage in Windhoek, Namibia. $S$ Afr $J$ Infect Dis. 2015;30:134-137.

14. Ocan M, Bwanga F, Bbosa GS, et al. Patterns and predictors of selfmedication in northern Uganda. PLoS One. 2014;9(3):e92323. doi:10.1371/journal.pone.0092323

15. Wiegand H, Kish L. Survey sampling. New York, London: John Wiley \& Sons, Inc.; 1965. IX + 643 S., 31 Abb., 56 Tab., Preis 83 s. Biom. Z. 10, 88-89 (1968).
16. Ferri M, Ranucci E, Romagnoli P, Giaccone V. Antimicrobial resistance: a global emerging threat to public health systems. Crit Rev Food Sci Nutr. 2017;57(13):2857-2876. doi:10.1080/ 10408398.2015.1077192

17. Wabulyu J. The state of patient safety in Uganda. Kampala, Uganda: Uganda Alliance of patients Organisations; 2019. Available from: https://isqua.org/world-patient-safety-day-blogs/the-state-of-patientsafety-in-uganda.html. Accessed May 28, 2021.

18. Obua TO, Adome RO, Kutyabami P, Kitutu FE, Kamba PF. Factors associated with occupancy of pharmacist positions in public sector hospitals in Uganda: a Cross-Sectional Study. Hum Resour Health. 2017;15(1). doi:10.1186/s12960-016-0176-x

19. Moienzadeh A, Massoud T, Black E. Evaluation of the general public's knowledge, views and practices relating to appropriate antibiotic use in Qatar. Int $J$ Pharm Pract. 2017;25(2):133-139. doi:10.1111/ijpp. 12233

20. Ong S, Nakase J, Moran GJ, et al. Antibiotic use for emergency department patients with upper respiratory infections: prescribing practices, patient expectations, and patient satisfaction. Ann Emerg Med. 2007;50(3):213-220. doi:10.1016/j.annemergmed.2007.03.026

21. Steinman MA, Landefeld CS, Gonzales R. Predictors of broad-spectrum antibiotic prescribing for acute respiratory tract infections in adult primary care. JAMA. 2003;289(719):719. doi:10.1001/jama.289.6.719

22. Núñez M, Tresierra-Ayala M, Gil-Olivares F. Antibiotic self-medication in university students from Trujillo, Peru. Med Univ. 2016;18:205-209.

23. Shaikhan F, Rawaf S, Majeed A, Hassounah S. Knowledge, attitude, perception and practice regarding antimicrobial use in upper respiratory tract infections in Qatar: a systematic review. JRSM Open. 2018;9(9):205427041877497. doi:10.1177/2054270418774971

24. Galdas PM, Cheater F, Marshall P. Men and health help-seeking behaviour: literature review. $J$ Adv Nurs. 2005;49(6):616-623. doi:10.1111/j.1365-2648.2004.03331.x

25. Oyediran OO, Ayandiran EO, Olatubi MI, Olabode O. Awareness of risks associated with self-medication among patients attending general out-patient department of a tertiary hospital in South Western Nigeria. Int J Africa Nurs Sci. 2019;10:110-115. doi:10.1016/j. ijans.2019.03.001

26. Kifle ZD, Mekuria AB, Anteneh DA, Enyew EF. Self-medication practice and associated factors among private health sciences students in Gondar Town, North West Ethiopia. A Cross-Sectional Study. Inquiry. 2021;58:004695802110051. doi:10.1177/00469580211005188

27. Ahmed SM, Sundby J, Aragaw YA, Abebe F. Self-medication and safety profile of medicines used among pregnant women in a tertiary teaching hospital in Jimma, Ethiopia: a Cross-Sectional Study. Int $J$ Environ Res Public Health. 2020;17(11):3993. doi:10.3390/ ijerph17113993
Infection and Drug Resistance

\section{Publish your work in this journal}

Infection and Drug Resistance is an international, peer-reviewed openaccess journal that focuses on the optimal treatment of infection (bacterial, fungal and viral) and the development and institution of preventive strategies to minimize the development and spread of resistance. The journal is specifically concerned with the epidemiology of antibiotic resistance and the mechanisms of resistance development and diffusion in both hospitals and the community. The manuscript management system is completely online and includes a very quick and fair peerreview system, which is all easy to use. Visit http://www.dovepress.com/ testimonials.php to read real quotes from published authors. 